\title{
AVALIAÇÃO DA EXATIDÃO TEMÁTICA DA COBERTURA E USO DA TERRA REPRESENTADA ATRAVÉS DO MAPBIOMAS NO RIO DE JANEIRO
}

Camila Lauria Zenke da Cruz ${ }^{1}$

Universidade Federal do Rio de Janeiro

Carla Bernadete Madureira Cruz ${ }^{2}$

Universidade Federal do Rio de Janeiro

Enviado em 31 out. 2020 | Aceito em 19 jan. 2021

Resumo: O conhecimento das interações entre os tipos de cobertura e uso da terra e seus padrões espaço-temporais é fundamental para orientar a utilização racional do espaço. $\mathrm{O}$ avanço significativo na disponibilidade de produtos de sensoriamento remoto e de técnicas de processamento em larga escala têm impulsionado o surgimento de importantes iniciativas, como o Projeto MapBiomas. Contudo, há a necessidade de ampliar o conhecimento sobre as vantagens e desvantagens dessas novas tecnologias e produtos. Assim, este estudo buscou compreender as potencialidades dessas novas abordagens através da comparação pixel a pixel dos Mapas de Uso e Cobertura dos Projetos MapBiomas e SEA/2015, este último usado como referência espacial, para duas áreas pilotos do Estado do Rio de Janeiro. Os resultados alcançados, com acurácia global de aproximadamente $85 \%$ para ambas as áreas de estudo, sugerem que os Mapas de Uso e Cobertura da Terra do Projeto MapBiomas apresentam alto grau de confiabilidade, e se posicionam no cenário atual, como um importante conjunto de dados e referência para a realização de mapeamentos temáticos.

Palavras-chave: Mapeamento Uso e Cobertura da Terra. MapBiomas. Acurácia Global.

\section{LAND USE AND LAND COVER THEMATIC ACCURACY EVALUATION REPRESENTED THROUGH MAPBIOMAS IN RIO DE JANEIRO STATE}

Abstract: Land Use and Land Cover Mappings are important tools to promote the rational use of space. The increase in the availability of remote sensing products, large-scale processing, and machine learning techniques have been promoting great initiatives, such as the MapBiomas Project. However, it is important to recognize the positive aspects and limitations of these new technologies and products. This study aims to better understand the potential of these new approaches through a pixel-by-pixel comparison between MapBiomas and SEA / 2015 LULC. SEA / 2015 LULC was used as a spatial and thematic reference for two pilot areas in the State of Rio de Janeiro. The results suggest that the MapBiomas Project achieved accuracy around $85 \%$ and a high level of reliability, and it is also an important source of geospatial data and reference for conducting thematic mappings.

Keywords: Thematic Mapping, MapBiomas, Land Use Land Cover Mapping.

\section{EVALUACIÓN DE LA PRECISIÓN TEMÁTICA DE LA COBERTURA Y USO DEL TERRENO REPRESENTADO A TRAVÉS DE MAPBIOMES EN RÍO DE JANEIRO}

Resumen: El conocimiento de las interacciones entre los tipos de cobertura y uso del suelo y sus patrones espacio-temporales es esencial para orientar el uso racional del espacio. El importante avance en la disponibilidad de productos de teledetección y técnicas de procesamiento a gran escala ha impulsado el surgimiento de importantes iniciativas, como el Proyecto MapBiomas. Sin embargo, es necesario ampliar el conocimiento sobre las ventajas y desventajas de estas nuevas tecnologías y productos. Así, este estudio buscó comprender el potencial de estos nuevos enfoques a través de la comparación píxel a píxel de los Mapas de Uso y Cobertura Map Biomas y SEA / 2015, este último utilizado como referencia espacial, para dos áreas piloto del Estado de Río. de Janeiro. Los resultados obtenidos, con una precisión general de aproximadamente el $85 \%$ para ambas áreas de estudio, sugieren que los Mapas de Cobertura y Uso del Suelo del Proyecto MapBiomas tienen un alto grado de confiabilidad, y están posicionados en el escenario actual, como un importante conjunto de datos y referencia para realización de mapeos temáticos.

Palabras clave: Uso del suelo y mapeo de cobertura. MapBiomas. Precisión global.

1. Mestranda do Programa de Pós-Graduação em Geografia pela Universidade Federal do Rio de Janeiro. E-mail: camilalzenke@gmail.com. ORCID: orcid.org/0000-0002-2364-6440.

2. Professora Titular e Coordenadora do Laboratório ESPAÇO de Sensoriamento Remoto e Estudos Ambientais. E-mail: carlamad@gmail.com. ORCID: orcid.org/0000-0002-3903-3147. 
Introdução

O conhecimento atualizado das formas de uso e de ocupação do espaço constitui um importante subsídio para a gestão territorial e orientação à tomada de decisão (IBGE, 2013). Os Mapeamentos de Uso e Cobertura da Terra contribuem para a compreensão da espacialização de elementos naturais e antrópicos, e os dados de imagens orbitais são importantes fontes para estes mapeamentos.

Com o avanço significativo na disponibilidade de novos produtos de sensoriamento remoto, bem como acervos de petabytes de imagens, emergiram os desafios para a manipulação eficiente de volumosos conjuntos de dados digitais. Atualmente, o investimento massivo em processamento dos dados, como a computação em nuvem e o uso de aprendizado de máquina, tem sido determinante para o escalonamento da informação geoespacial, possibilitando conquistas recentes como a realização de análises complexas, de grandes áreas e períodos de aproximadamente 40 anos. Neste cenário, surgem soluções apoiadas em processamento em larga escala e bibliotecas de códigos abertos, como a Plataforma de Tecnologia Google Earth Engine (GORELICK et al, 2017).

Importantes iniciativas para o Mapeamento de Uso e Cobertura da Terra, em escalas regionais, estão em desenvolvimento com o suporte dessas novas abordagens, como o Projeto MapBiomas (http://mapbiomas.org/). Contudo, atualmente, há a necessidade de ampliar o conhecimento sobre as vantagens e desvantagens dessas novas tecnologias e produtos. Explorar os novos métodos pode possibilitar variados estudos geográficos em diferentes escalas espaciais e temporais. Esses, por sua vez, podem atender à demandas conhecidas pelos brasileiros, como a realização e implementação de uma gestão territorial e ambiental efetivas.

Assim, a avaliação do Mapa de Uso e Cobertura da Terra de 2015 do Projeto MapBiomas foi realizada através da comparação pixel a pixel com o Mapa de Uso e Cobertura da Terra da SEA / UFRJ do mesmo ano, nas escalas de 1:25.000 e 1:100.000. Considerando que o uso e ocupação apresentam dinâmicas que são influenciadas de acordo com o contexto socioeconômico em que estão inseridos, as Regiões Hidrográficas $(\mathrm{RH})$ foram adotadas como unidades espaciais desta análise. As RHs III e V foram selecionadas como áreas pilotos por apresentarem os três contextos socioeconômicos relevantes: agropastoril, urbano e de conservação (florestal).

\section{Mapeamento do Uso e Cobertura em Escala 1:100.000 - MapBiomas}

Lançado em 2015, o MapBiomas é uma iniciativa brasileira que envolve diversos atores como instituições públicas, ONGs, universidades e empresas de tecnologia, com o propósito de disponibilizar, gratuitamente, mapas anuais de uso e cobertura da terra de todo o Brasil, em escalas até 1:100.000 (pixel de 30x30m), a fim de contribuir para o entendimento das transformações em escala nacional e para a diminuição da emissão de gases do efeito estufa pelo país.

Com especialistas dos biomas brasileiros, uso da terra, sensoriamento remoto, SIG e ciência da computação, este projeto se apoia no processamento em nuvem e classificadores automatizados, desenvolvidos e operados a partir da plataforma Google Earth Engine. Como resultado, é construída 
e disponibilizada uma série histórica de mapas anuais de cobertura e uso da terra do Brasil, desde 1985 até os dias atuais. (PROJETO MAPBIOMAS, 2019).

Esta iniciativa tem o objetivo de contribuir para o entendimento da dinâmica do uso da Terra no Brasil através do desenvolvimento e implementação de metodologias apoiadas em processamento em larga escala e de baixo custo financeiro. Este projeto também conta com a criação de uma plataforma gratuita e online para facilitar a disseminação da metodologia para outros países e regiões interessadas, utilizando a mesma base de algoritmos, bem como divulgação e aquisição de seus produtos e resultados, a fim de universalizar o acesso às informações geoespaciais e de uso e cobertura da Terra no Brasil.

\section{Mapeamento do Uso e Cobertura em Escala 1:25.000 - SEA / INEA}

O Projeto de Mapeamento da Cobertura da Terra e de Detecção de Mudanças na Cobertura Florestal do Estado do Rio de Janeiro (2018) originou, dentre outros produtos, o Mapa de Uso e Cobertura da Terra do Estado do Rio de Janeiro na escala de 1:25.000 e pixel de 2x2m para o ano de 2015.

Este mapeamento foi embasado no imageamento orbital através de diferentes sensores de alta resolução espacial (50 cm), focando o ano base de 2014士1 (2013 a 2015, preferencialmente). Pela complexidade do tamanho da área mapeada (aproximadamente $45.988 \mathrm{~km}^{2}$ ) e do detalhamento requerido ( $0,5 \mathrm{ha})$, diferentes soluções foram desenvolvidas, como a integração de sensores distintos objetivando atender às peculiaridades de cada classe, a dinâmica temporal e a melhor caracterização espectral e espacial (SEA / INEA, 2018).

O Mapa de Uso e Cobertura da Terra / SEA 2015 atingiu 100\% da identificação de classes, pois foram usados recursos alternativos para suprir lacunas oriundas da presença de nuvens e excesso de sombreamento. Em adição, este projeto contou com a realização de muitos trabalhos de campo; um rigoroso processo de avaliação, sem o conhecimento prévio da classe mapeada; e uma criteriosa validação, envolvendo de dois a três intérpretes para cada Região Hidrográfica.

Os resultados encontrados (Kappa de 0,85) demonstram a assertividade dos processos metodológicos desenvolvidos bem como alto grau de exatidão e nível de confiabilidade deste produto, que foi utilizado neste estudo como mapa de referência para as análises pixel a pixel e comparação com o produto MapBiomas do mesmo ano.

\section{Área de estudo}

A escolha das Regiões Hidrográficas Médio Vale do Paraíba do Sul (RH-III) e Baía de Guanabara $(\mathrm{RH}-\mathrm{V})$, se deu por essas apresentarem os três cenários socioambientais e econômicos distintos conservação, agropastoril e urbano (SEA / INEA, 2014). A Erro! Fonte de referência não encontrada.Figura 1 apresenta as Regiões Hidrográficas do Estado do Rio de Janeiro escolhidas para o desenvolvimento deste estudo. 
Figura 1 - Áreas de Estudo

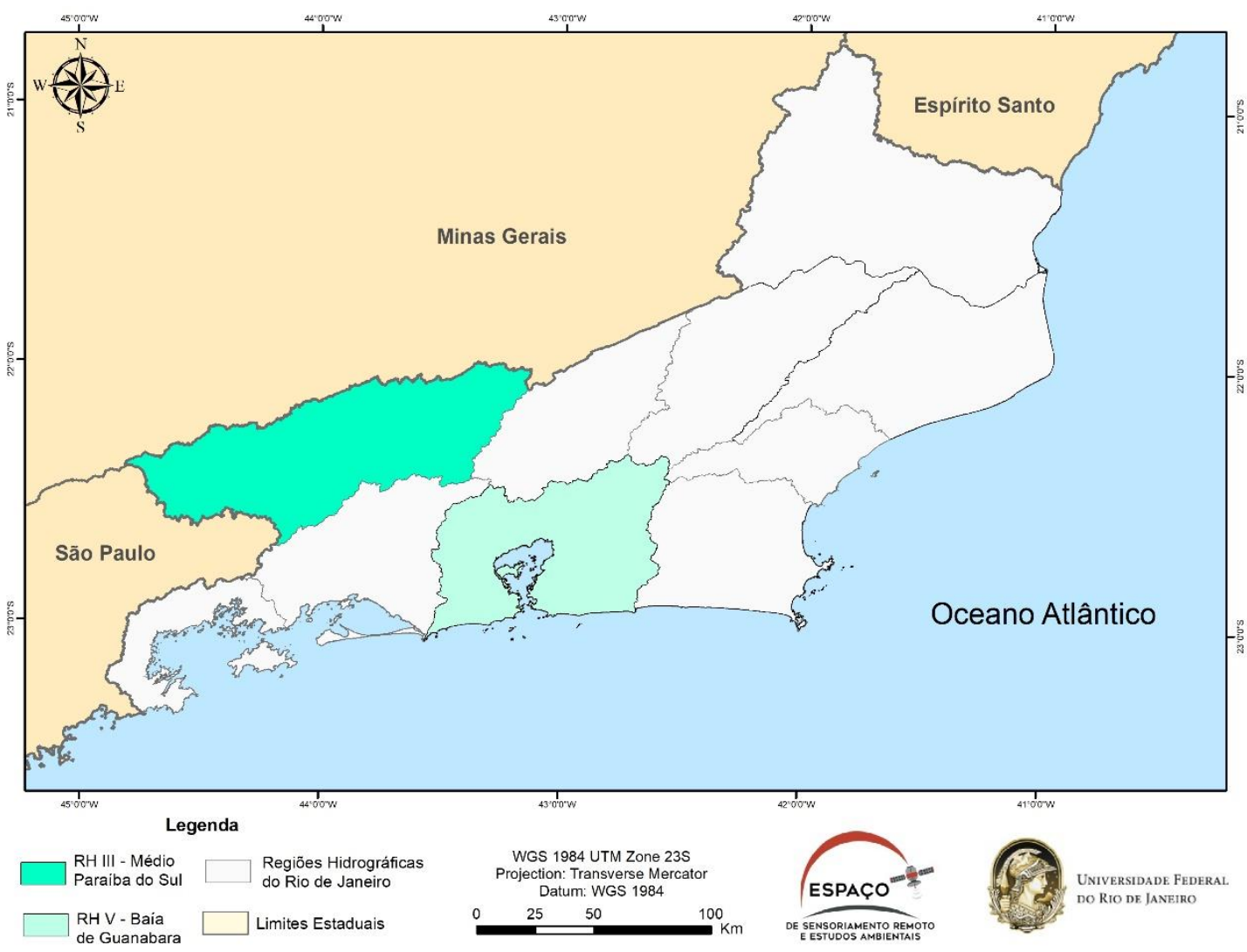

Fonte: confecção dos autores.

A RH-III apresenta a maior proporção de terras ocupadas por pastagens (69\%) e, por essa razão, foi selecionada para representar o cenário "agropastoril". Sua população total foi estimada em 979.023 habitantes, a maior parte residente em Volta Redonda - 26\%, Barra Mansa - 18\%, e Resende - 12\% (Censo IBGE 2010 apud SEA / INEA, 2014). Seus municípios possuem uma economia voltada para agropecuária e turismo rural, devido ao resquício da infraestrutura construída na época do café.

Já a RH-V é o ponto central da ocupação e desenvolvimento urbano do estado, representado pela capital e toda a Região Metropolitana, às quais se conectam vetores de expansão para as Regiões Hidrográficas limítrofes (SEA / INEA, 2014). Na RH-V reside a maior parte da população urbana do estado, cerca de 10.143.250 habitantes, dos quais 51\% se concentram no município do Rio de Janeiro (Censo IBGE 2010 apud SEA / INEA, 2014). Além disso, nesta região estão localizados importantes remanescentes de Mata Atlântica protegidos por Unidades de Conservação, como o Parque Nacional da Tijuca e o Parque Estadual da Pedra Branca.

\section{Materiais}

A avaliação do Mapa de Uso e Cobertura da Terra de 2015 do Projeto MapBiomas foi realizada através da comparação pixel a pixel com o Mapa de Uso e Cobertura da Terra da SEA / UFRJ do mesmo ano, nas escalas de 1:25.000 e 1:100.000. Para isso, este processo contou, primeiramente, com a aquisição e organização dos dados: 
- SEA: Mapa de Uso e Cobertura do Estado do Rio de Janeiro de 2015, escala 1:25.000, cedido gratuitamente pelo Laboratório Espaço de Sensoriamento Remoto e Estudos Ambientais, UFRJ.

- MapBiomas: Aquisição gratuita da Versão 4.0 do Mapa de Uso e Cobertura do Bioma Mata Atlântica, escala 1:100.000, ano de 2015, através da plataforma MapBiomas (https://mapbiomas.org/).

\section{Metodologia}

\section{Definição e Adequação da Legenda Temática}

As legendas de Uso e Cobertura da Terra compreendem um conjunto de informações relativas às classes caracterizadas e às tecnologias aplicadas. As tipologias da Cobertura e do Uso da Terra devem ser representadas segundo a escala pretendida. Em função dessa escala existirá um maior ou menor detalhamento na construção da legenda (IBGE, 2013).

Segundo o IBGE (2013), a Cobertura da Terra indica áreas de predomínio das características naturais ou construídas/produzidas. Quando se tratar de áreas sob legislação específica, essas serão representadas pelo uso atribuído pela lei, a exemplo das áreas especiais de conservação/preservação e terras indígenas. Já as áreas sob utilização econômica são reconhecidas como padrões de Uso da Terra, entendido como uma representação sintética de um conjunto de atividades econômicas com expressão espacial que, de alguma forma, interagem no espaço.

A elaboração preliminar da Legenda Temática serve como base de identificação ou guia durante o mapeamento, além de auxiliar a identificação das etapas e o planejamento para a construção ou execução de um método de análise. Com o decorrer do desenvolvimento dos mapeamentos, a legenda passa por várias modificações e atualizações de acordo com as informações adquiridas, a fim de proporcionar a melhor caracterização das unidades de Uso e Cobertura da Terra (IBGE, 1999).

O presente estudo buscou compreender o nível de exatidão do método e produto desenvolvidos pelo Projeto MapBiomas para duas áreas pilotos e três matrizes espaciais predominantes: urbano, agropastoril e de conservação (florestal). Por esses motivos, definiu-se que a Legenda Temática representaria as seguintes unidades de mapeamento: Áreas Antrópicas Agropastoris (AAA), Áreas Antrópicas Não Agropastoris (AANA), Cobertura Florestal (CF) e Outros.

A classe Áreas Antrópicas Agropastoris (AAA) corresponde às áreas de uso para a produção de alimentos, fibras ou outras matérias-primas que podem ser empregadas na indústria. Inclui todas as terras cultivadas, caracterizadas pelo delineamento de áreas cultivadas ou em descanso, podendo também compreender áreas alagadas. Podem se constituir em zonas agrícolas heterogêneas ou representar extensas áreas de plantations. Encontram-se inseridas nesta categoria as lavouras temporárias, lavouras permanentes e pastagens plantadas (IBGE, 2013).

Na classe Áreas Antrópicas Não Agropastoris (AANA), reúnem-se as coberturas referentes às áreas abertas construídas, onde predominam edificações que caracterizam processos de expansão urbana, complexos industriais, áreas urbanizadas, áreas de mineração ou extração mineral e outras coberturas não agropastoris. Compreendem áreas de uso intensivo, estruturadas por edificações e sistema viário, onde predominam as superfícies artificiais não agrícolas (IBGE, 2013). Foram consideradas as áreas correspondentes às cidades (sedes municipais), às vilas (sedes distritais), às áreas urbanas isoladas e as áreas relacionadas às atividades de extração mineral. 
A classe Cobertura Florestal (CF) congrega uma série de fisionomias da vegetação natural: "florestais" (porte arbóreo) e "campestres" (portes arbustivo e herbáceo). Abrange as fisionomias da Floresta Densa (estrutura florestal com cobertura superior contínua), da Floresta Aberta (estrutura florestal com diferentes graus de descontinuidade da cobertura superior, conforme seu tipo (com cipó, bambu, palmeira ou sororoca), da Floresta Estacional (estrutura florestal com perda das folhas dos estratos superiores durante a estação desfavorável - seca e frio - (IBGE, 2013). Este título também inclui áreas remanescentes primárias, estágios evoluídos de recomposição florestal e silvicultura.

Por fim, a classe Outros refere-se às áreas descobertas, tanto de ambientes naturais, quanto de ambientes antrópicos, decorrentes da degradação provocada pelas atividades humanas (IBGE, 2013). Neste mapeamento, a classe Outros engloba coberturas como: Água, Áreas Úmidas, Afloramento Rochoso, Solo Exposto e Praias.

Sendo assim, foi necessário realizar a adequação da legenda temática dos mapeamentos analisados neste estudo (SEA e MapBiomas), equiparando e agregando das Classes de Uso e Cobertura da Terra. A Tabela 1 a seguir apresenta o resultado desta etapa.

Tabela 1 - Adequação da Legenda Temática

\begin{tabular}{|c|c|c|}
\hline Legenda SEA & Legenda Mapbiomas & Legenda Final \\
\hline $\begin{array}{c}\text { Áreas Antrópica Agropastoril, Áreas } \\
\text { Antrópicas Agropastoris Não } \\
\text { Consolidadas. }\end{array}$ & $\begin{array}{c}\text { Pasto, Cultura Anual Perene, } \\
\text { Mosaico de Agricultura e } \\
\text { Pastagem. }\end{array}$ & $\begin{array}{c}\text { Áreas Antrópicas Agropastoris - } \\
\text { AAA. }\end{array}$ \\
\hline $\begin{array}{l}\text { Área Antrópica Não Agropastoril } \\
\text { (Área de Urbanização). }\end{array}$ & Área de Urbanização, Mineração. & $\begin{array}{l}\text { Áreas Antrópicas Não } \\
\text { Agropastoris - AANA. }\end{array}$ \\
\hline $\begin{array}{c}\text { Área Natural Florestada, Restinga, } \\
\text { Mangue, Silvicultura. }\end{array}$ & $\begin{array}{l}\text { Formação Florestal, Floresta } \\
\text { Plantada, Mangue. }\end{array}$ & Cobertura Florestal - CF. \\
\hline Área Natural Não Florestada, Água. & $\begin{array}{c}\text { Rios, Lagos, Oceano, Apicum, } \\
\text { Afloramento Rochoso, Praias e } \\
\text { Dunas, Outra Área não vegetada, } \\
\text { Outra Formação Natural Não } \\
\text { Florestal. }\end{array}$ & Outros. \\
\hline
\end{tabular}

\section{Definição da Escala de Análise}

Estudos mais acurados e precisos sobre uso e cobertura da Terra necessitam considerar a problemática acerca da escala ideal para a análise a ser desenvolvida. Para entender como as paisagens afetam e são afetadas pelas atividades biofísicas e socioeconômicas, Wu (2004) aponta que a capacidade de qualificar e quantificar a heterogeneidade espacial é atrelada à escala de análise, o que permite afirmar que respostas como padrões, geometria, área e distribuição mudam de acordo com a escala.

Woodcock \& Strahler (1987) complementam este contexto ao apontarem outros fatores para a escolha apropriada da escala de análise da paisagem e consequente bem-sucedida implementação de sistemas de mapeamento: os métodos usados para extração das informações das imagens; a estrutura espacial do objeto na cena e tipo de ambiente a ser investigado. 
Esses fatores associam-se a outro elemento fundamental: o conhecimento da resolução espacial a ser adotada. Lang \& Blaschke (2009) afirmam que a resolução espacial de dados observados desenvolve um importante papel na identificação e análise dos elementos constituintes da paisagem. Portanto, a seleção da escala e da resolução espacial é um fator importante que contribuirá para a aplicação bem-sucedida do sensoriamento remoto na identificação dos elementos, estruturas e até níveis hierárquicos da paisagem.

A avaliação do Mapa de Uso e Cobertura da Terra de 2015 do Projeto MapBiomas foi realizada através da comparação pixel a pixel com o Mapa de Uso e Cobertura da Terra da SEA / UFRJ do mesmo ano, nas escalas de 1:25.000 e 1:100.000. Para essa análise, realizada através da ferramenta Combine no software ArcGis10.5, foi necessário generalizar os produtos para as respectivas escalas de compatibilidade através da reamostragem do tamanho do pixel. As escalas de $1.25 .000 \mathrm{e}$ 1.100 .000 e os tamanhos de pixel de $2 \times 2 \mathrm{~m}$ e $30 \times 30 \mathrm{~m}$ foram adotados a fim de manter as características estruturais de ambos os mapeamentos.

Assim, o Mapeamento da SEA foi generalizado para a escala de 1:100:000, através da reamostragem do tamanho do pixel, de $2 \times 2 \mathrm{~m}$ para $30 \times 30 \mathrm{~m}$, utilizando-se a moda para a atribuição da classe final. O mesmo ocorreu para o Mapeamento do MapBiomas, que teve o seu pixel reamostrado de $30 \times 30 \mathrm{~m}$ para $2 \times 2 \mathrm{~m}$, compatível com a escala de 1.25 .000 , embora neste caso tenha sido uma simples divisão de pixel objetivando apenas a integração direta entre matrizes. É importante destacar que a simplificação e ampliação da escala, de 1:100.000 para 1.25.000, normalmente resultam em alteração das classes temáticas, interferindo nos resultados finais.

\section{Resultados}

Através do estabelecimento do Mapeamento da SEA como referência e da construção da matriz de confusão (CONGALTON \& GREEN, 1999), foram calculadas para cada classe: Acurácia Global, Acurácia do Usuário e Acurácia do produtor. A Figura 2 e Figura 3 apresentam os resultados da comparação pixel a pixel e da Matriz de Confusão da RH III, e a Figura 4 e Figura 5, da Matriz de Confusão da RH V.

Figura 2 - Matriz de Confusão para RH III, na escala de 1:25.000 entre os Mapas de Uso e Cobertura da Terra do Mapbiomas e SEA, para o ano de 2015

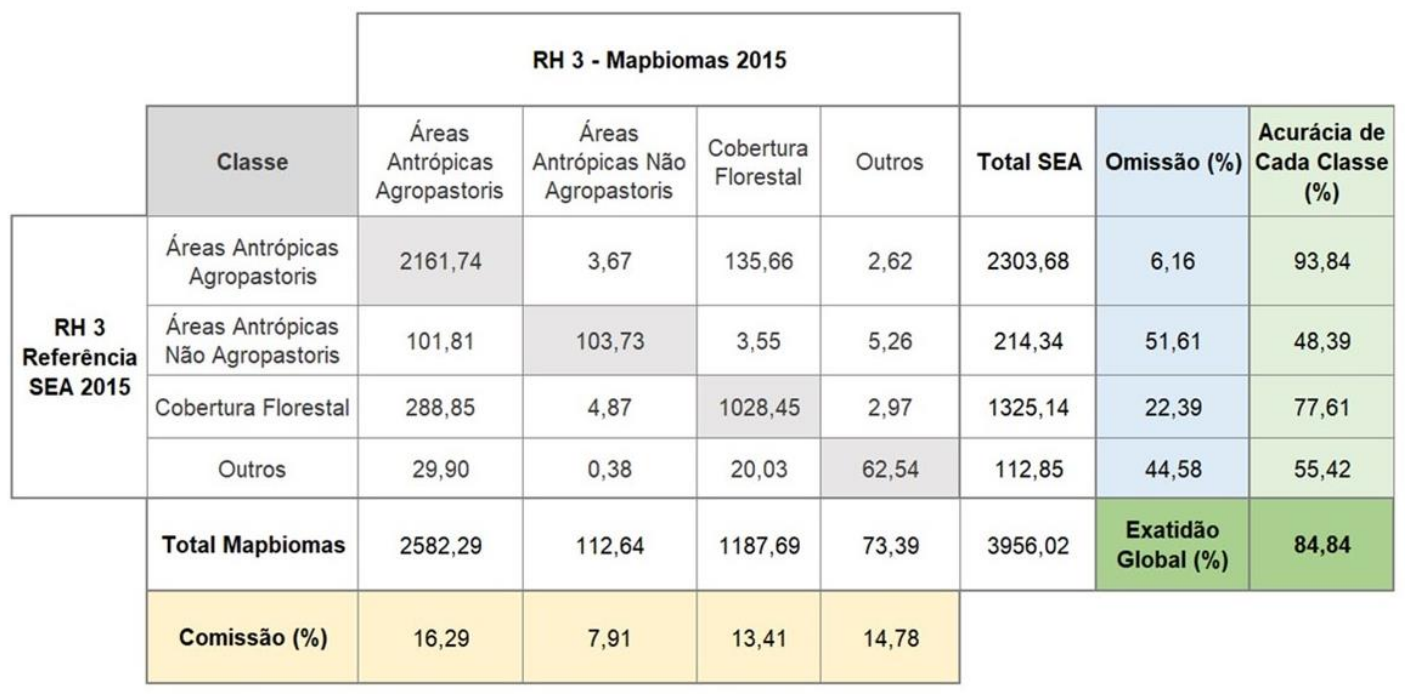

Fonte: confecção dos autores. 
Figura 3 - Matriz de Confusão para RH III, na escala de 1:100.000 entre os Mapas de Uso e Cobertura da Terra do Mapbiomas e SEA, para o ano de 2015

\begin{tabular}{|c|c|c|c|c|c|c|c|c|}
\hline & & \multicolumn{4}{|c|}{ RH 3 - Mapbiomas 2015} & \multirow[b]{2}{*}{ Total SEA } & \multirow[b]{2}{*}{$\begin{array}{l}\text { Omissão } \\
\text { (\%) }\end{array}$} & \multirow[b]{2}{*}{$\begin{array}{c}\text { Acuracia } \\
\text { de Cada } \\
\text { Classe (\%) }\end{array}$} \\
\hline & Classe & $\begin{array}{c}\text { Áreas } \\
\text { Antrópicas } \\
\text { Agropastoris }\end{array}$ & $\begin{array}{c}\text { Áreas } \\
\text { Antrópicas Não } \\
\text { Agropastoris }\end{array}$ & $\begin{array}{l}\text { Cobertura } \\
\text { Florestal }\end{array}$ & Outros & & & \\
\hline \multirow{4}{*}{$\begin{array}{c}\text { RH } 3 \\
\text { Referência - } \\
\text { SEA } 2015\end{array}$} & $\begin{array}{c}\text { Áreas Antrópicas } \\
\text { Agropastoris }\end{array}$ & 2134,83 & 3,59 & 126,20 & 2,30 & 2266,92 & 5,83 & 94,17 \\
\hline & $\begin{array}{l}\text { Áreas Antrópicas } \\
\text { Não Agropastoris }\end{array}$ & 99,97 & 102,34 & 3,38 & 5,24 & 210,93 & 51,48 & 48,52 \\
\hline & $\begin{array}{l}\text { Cobertura } \\
\text { Florestal }\end{array}$ & 277,25 & 4,61 & 1019,69 & 2,49 & 1304,05 & 21,81 & 78,19 \\
\hline & Outros & 28,86 & 0,37 & 19,50 & 62,23 & 110,95 & 43,92 & 56,08 \\
\hline & Total RF & 2540,90 & 110,91 & 1168,78 & 72,26 & 3892,85 & $\begin{array}{l}\text { Exatidão } \\
\text { Global (\%) }\end{array}$ & 85,26 \\
\hline & Comissão (\%) & 15,98 & 7,73 & 12,76 & 13,89 & & & \\
\hline
\end{tabular}

Fonte: confecção dos autores.

Figura 4 - Matriz de Confusão para RH V, na escala de 1:25.000 entre os Mapas de Uso e Cobertura da Terra do Mapbiomas e SEA, para o ano de 2015

\begin{tabular}{|c|c|c|c|c|c|c|c|c|}
\hline & & \multicolumn{4}{|c|}{ RH 5 - Mapbiomas 2015} & \multirow[b]{2}{*}{ Total SEA } & \multirow[b]{2}{*}{ Omissão (\%) } & \multirow[b]{2}{*}{$\begin{array}{r}\text { Acurácia } \\
\text { de Cada } \\
\text { Classe (\%) }\end{array}$} \\
\hline & Classe & $\begin{array}{c}\text { Áreas Antrópicas } \\
\text { Agropastoris }\end{array}$ & $\begin{array}{c}\text { Áreas Antrópicas } \\
\text { Não } \\
\text { Agropastoris }\end{array}$ & $\begin{array}{l}\text { Cobertura } \\
\text { Florestal }\end{array}$ & Outros & & & \\
\hline \multirow{6}{*}{$\begin{array}{c}\text { RH } 5 \\
\text { Referência - } \\
\text { SEA 2015 }\end{array}$} & $\begin{array}{c}\text { Áreas Antrópicas } \\
\text { Agropastoris }\end{array}$ & 1240,69 & 16,87 & 58,96 & 2,13 & 1318,65 & 5,91 & 94,09 \\
\hline & $\begin{array}{l}\text { Áreas Antrópicas } \\
\text { Não Agropastoris }\end{array}$ & 218,01 & 1080,60 & 17,34 & 9,07 & 1325,02 & 18,45 & 81,55 \\
\hline & Cobertura Florestal & 314,92 & 24,23 & 1871,26 & 6,33 & 2216,73 & 15,58 & 84,42 \\
\hline & Outros & 76,27 & 9,59 & 26,73 & 281,96 & 394,55 & 28,53 & 71,47 \\
\hline & Total Mapbiomas & 1849,89 & 1131,29 & 1974,29 & 299,49 & 5254,95 & $\begin{array}{l}\text { Exatidão } \\
\text { Global (\%) }\end{array}$ & 85,15 \\
\hline & Comissão (\%) & 32,93 & 4,48 & 5,22 & 5,85 & & & \\
\hline
\end{tabular}

Fonte: confecção dos autores. 
Figura 5 - Matriz de Confusão para RH V, na escala de 1:100.000 entre os Mapas de Uso e Cobertura da Terra do Mapbiomas e SEA, para o ano de 2015

\begin{tabular}{|c|c|c|c|c|c|c|c|c|}
\hline & & \multicolumn{4}{|c|}{ RH 5 - Mapbiomas 2015} & \multirow[b]{2}{*}{ Total SEA } & \multirow[b]{2}{*}{$\begin{array}{c}\text { Omissão } \\
(\%)\end{array}$} & \multirow[b]{2}{*}{$\begin{array}{c}\text { Acuracia de } \\
\text { Cada Classe } \\
(\%)\end{array}$} \\
\hline & Classe & $\begin{array}{c}\text { Áreas } \\
\text { Antrópicas } \\
\text { Agropastoris }\end{array}$ & $\begin{array}{c}\text { Áreas } \\
\text { Antrópicas } \\
\text { Não } \\
\text { Agropastoris }\end{array}$ & $\begin{array}{l}\text { Cobertura } \\
\text { Florestal }\end{array}$ & Outros & & & \\
\hline \multirow{6}{*}{$\begin{array}{c}\text { RH } 5 \\
\text { Referência - } \\
\text { SEA } 2015\end{array}$} & $\begin{array}{c}\text { Áreas Antrópicas } \\
\text { Agropastoris }\end{array}$ & 1234,60 & 16,57 & 55,17 & 2,10 & 1308,44 & 5,64 & 94,36 \\
\hline & $\begin{array}{l}\text { Áreas Antrópicas } \\
\text { Não Agropastoris }\end{array}$ & 215,82 & 1074,21 & 16,30 & 8,76 & 1315,09 & 18,32 & 81,68 \\
\hline & Cobertura Florestal & 308,74 & 23,34 & 1860,71 & 6,01 & 2198,79 & 15,38 & 84,62 \\
\hline & Outros & 75,99 & 9,26 & 26,19 & 282,21 & 393,65 & 28,31 & 71,69 \\
\hline & Total RF & 1835,14 & 1123,38 & 1958,37 & 299,06 & 5215,96 & $\begin{array}{l}\text { Exatidão } \\
\text { Global (\%) }\end{array}$ & 85,35 \\
\hline & Comissão (\%) & 32,72 & 4,38 & 4,99 & 5,64 & & & \\
\hline
\end{tabular}

Fonte: confecção dos autores.

Os resultados apontam que o produto MapBiomas apresentou, para a RH III, acurácia global de $84,84 \%$ na escala 1:25.000 e 85,26\% na escala 1:100.000, ambas consideradas "Excelente" de acordo com Congalton \& Green (2009). As classes que apresentaram melhor desempenho de classificação foram: Áreas Antrópicas Agropastoris e Cobertura Florestal, com exatidão de 93,84\% (1:25.000) $94,17 \%$ (1:100.000), 77,61\% (1:25.000) e 78,19\% (1:100.000), respectivamente. Acredita-se que a obtenção destes valores se deve a sensibilidade do classificador em delimitar as duas classes. Já Áreas Antrópicas Não Agropastoris e Outros apresentam menor nível de exatidão, decorrente da menor consolidação das áreas urbanas e da topografia da região, que resulta em áreas sombreadas que se confundem com a resposta espectral de outros alvos, como afloramento rochoso, solo exposto e floresta.

Para a RH V, os resultados também apontam para o nível "Excelente" de acordo com Congalton \& Green (2009), com acurácia global de 85,15\% na escala 1:25.000 e 85,35\% na escala 1:100.000. As classes Áreas Antrópicas Agropastoris, Áreas Antrópicas Não Agropastoris e Cobertura Florestal atingiram desempenho superior a $80 \%$ de exatidão em ambas as escalas de análise. A obtenção destes valores está relacionada às características de distribuição espacial da própria $\mathrm{RH} V$, onde os usos e coberturas da Terra apresentam maior consolidação e delimitação espacial.

Essa análise apontou que, o Mapa de Uso e Cobertura da Terra de 2015 do Projeto MapBiomas, apresenta alto nível de confiabilidade, com acurácia global considerada excelente para ambas as áreas de estudo, tanto na escala de 1:25.000 quanto 1:100.000. As classes que apresentaram maior exatidão foram Áreas Antrópicas Agropastoris e Cobertura Florestal, demonstrando a sensibilidade do produto em diferenciá-las, principalmente em regiões com predomínio da matriz agropastoril.

Por fim, atendendo ao objetivo de adequação da escala de análise, esta etapa identificou que a escala de 1:100:000, junto com e resolução espacial de 30 metros (pixel de 30m X 30m), atingiu maior exatidão na comparação pixel a pixel com o mapeamento de Referência (SEA / 2015). A escala de análise 1:100.000 também apresentou potencialidades como menor custo computacional, de armazenamento e menor tempo de processamento. Esta escala de análise também apresenta grande compatibilidade com a identificação de padrões, geometria, área e distribuição de áreas agrícolas, urbanas e florestadas nos contextos referentes às $\mathrm{RH}$ s III e V. 
A Figura 6, Figura 7, Figura 8 e Figura 9 apresentam a exatidão temática do Mapa de Uso e Cobertura do Mapbiomas em relação ao Mapa de Uso e Cobertura SEA / 2015, para as RHs III e V, na escala de 1:100.000, evidenciando as diferenças entre as metodologias adotadas por ambos os mapeamentos.

Figura 6 - Mapa de Uso e Cobertura da Terra SEA/ UFRJ, RH III, ano de 2015

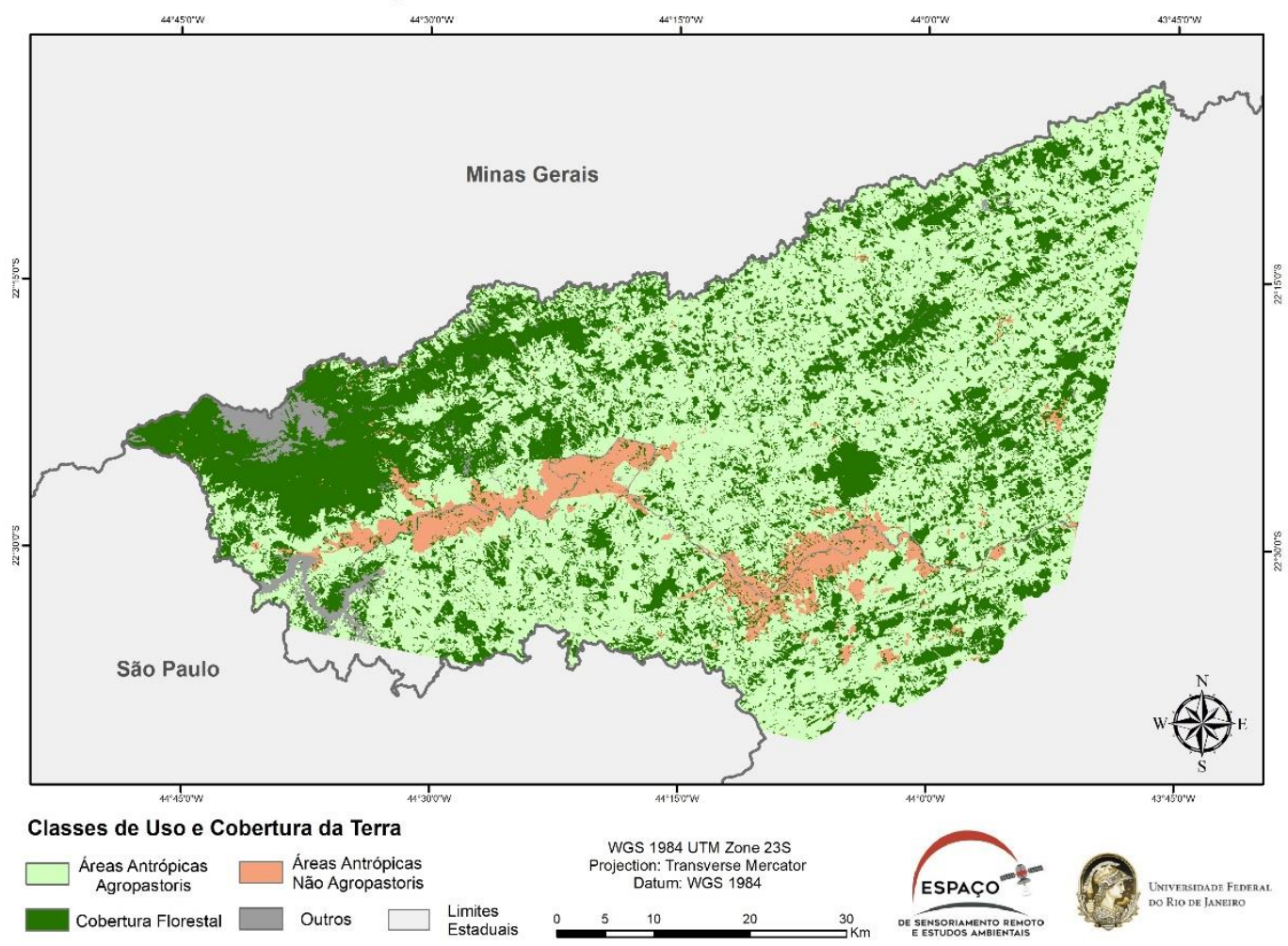

Figura 7 - Mapa de Uso e Cobertura da Terra MapBiomas, RH III, ano de 2015

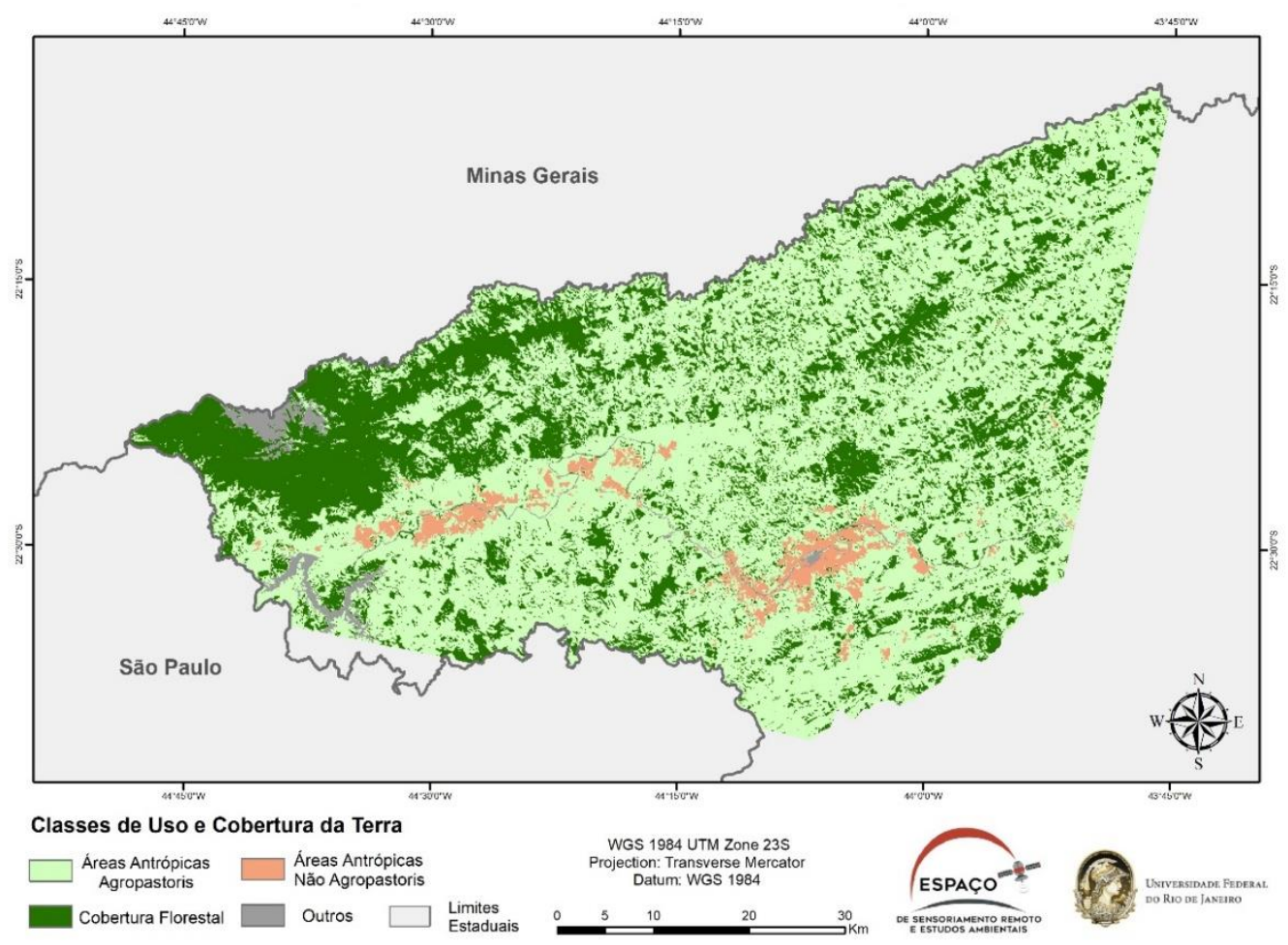

Fonte: confecção dos autores. 
Figura 8 - Mapa de Uso e Cobertura da Terra SEA/ UFRJ, RH V, ano de 2015

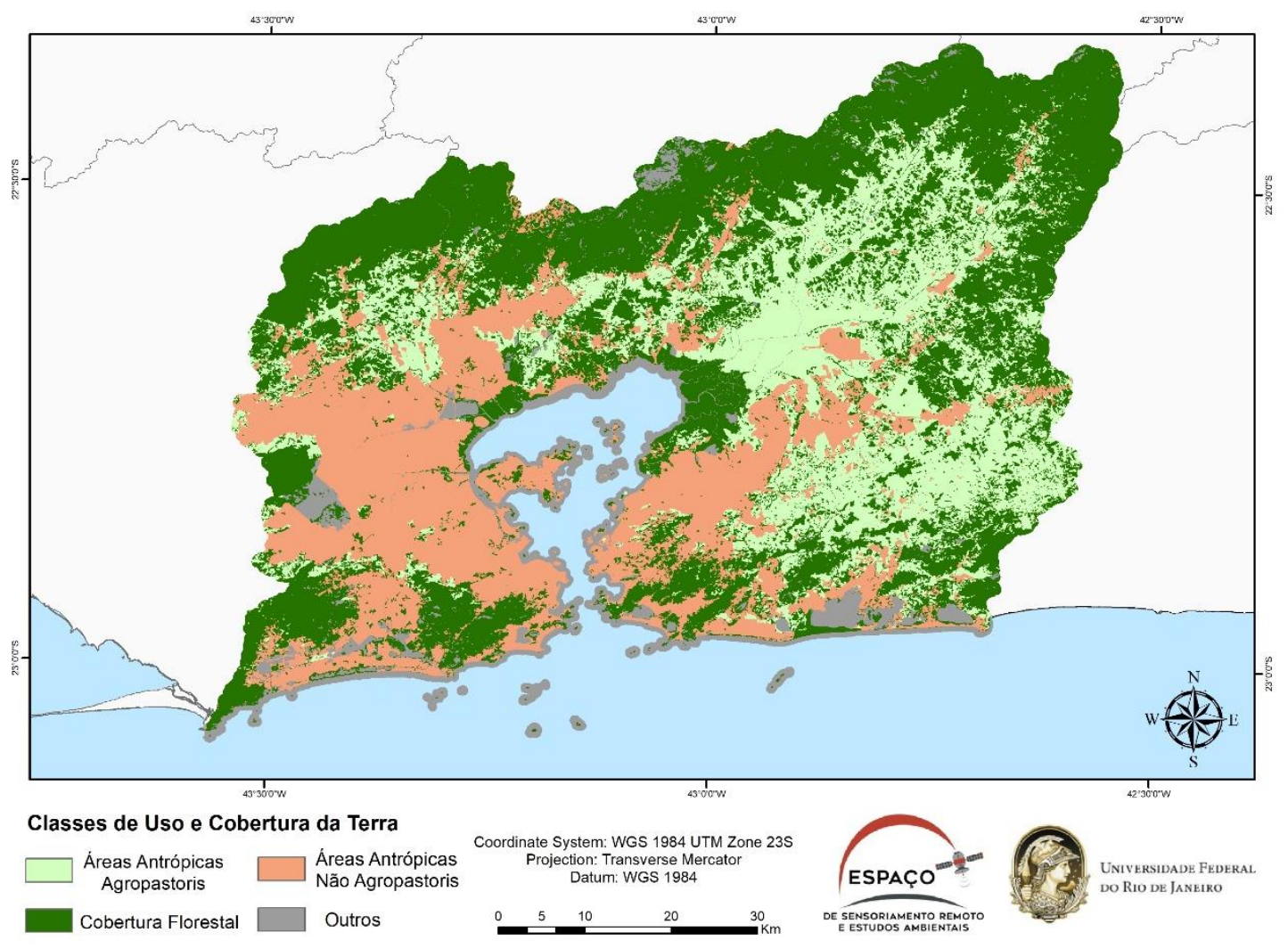

Figura 9 - Mapa de Uso e Cobertura da Terra MapBiomas, RH V, ano de 2015

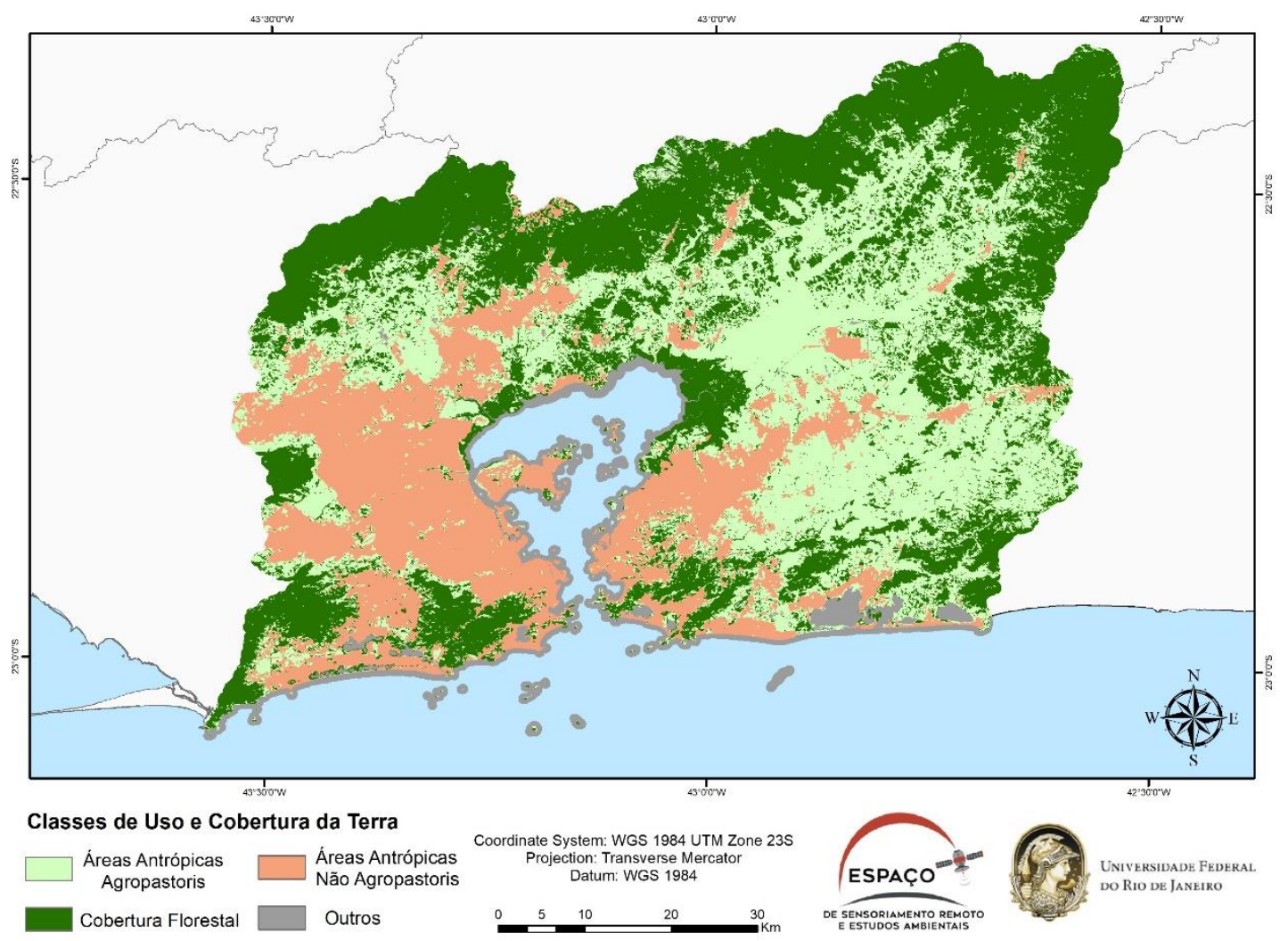

Fonte: confecção dos autores. 
Sabe-se que comparação de mapeamentos de diferentes escalas deve sempre considerar o processo de generalização geométrica e de classes dos produtos, de modo que a análise efetuada seja coerente em termos das similitudes e diferenças entre os resultados obtidos. Para o caso das análises efetuadas no presente trabalho, partiu-se de uma alta correlação entre as classes de mapeamento de ambos os produtos, tendo-se que ter um maior cuidado com as questões geométrica, ou de escala, envolvidas.

Apesar de não ser o ideal, a principal vantagem de uma análise cruzada desta natureza, é que é possível considerar $100 \%$ da área mapeada, não se limitando a poucas amostras pontuais, mesmo que selecionadas aleatoriamente. Considerou-se neste trabalho o rigor de representação do mapeamento da SEA, não somente por sua maior escala, mas por este ter passado por um processo rigoroso de validação e de visitas a campo. Desta forma, mesmo cientes de que uma comparação desta natureza traria mais chances de ser contaminada por possíveis problemas de generalização e mistura oriundas do uso de um sensor de resolução espacial menor, os resultados obtidos comprovam que, no geral, os mapeamentos do projeto MapBiomas atendem às especificações normalmente esperadas para o uso de produtos temáticos, principalmente se considerarmos a abrangência espacial e temporal dos dados gerados.

\section{Considerações finais}

Os resultados alcançados sugerem que os Mapas de Uso e Cobertura da Terra do Projeto MapBiomas, para o ano de 2015, apresentam alto grau de confiabilidade e se posicionam como um importante conjunto de dados e referência para a realização de mapeamentos temáticos, considerando outras datas, e como instrumento de validação espacial e estatística para as Regiões Hidrográficas III e V. Os dados utilizados no presente estudo foram adquiridos gratuitamente através da plataforma do Projeto, o que contribui para a disseminação e universalização de dados e informações geoespaciais sobre o território brasileiro, para o período de 1985 - 2018.

É importante ressaltar que os dados adotados em cada mapeamento têm naturezas distintas em relação ao detalhamento espacial e às abordagens de classificação adotadas. Assim, a possibilidade de se efetuar trabalhos de campo também é importante, dado a diferença na abrangência de ambos os projetos. Este estudou também realizou a comparação de áreas totais, mas sabe-se que o nível de detalhamento de cada escala, em termos de área mínima, varia muito. Assim, a escolha da escala dependerá da finalidade da análise e do objeto ou fenômeno de interesse.

O objetivo deste estudo consistiu em compreender as potencialidades dessas novas abordagens e produtos, pois entende-se que a apresentação e disseminação de métodos técnicocientíficos através do sensoriamento remoto, podem ser importantes instrumentos para a elaboração de programas de monitoramento, redução de impactos socioambientais negativos, e legislações voltadas para a proteção e melhor gestão dos recursos naturais. Além disso, compreender os fluxos analíticos e as mudanças paradigmáticas que estes novos mecanismos impõem não só aos pesquisadores, mas a Ciência Geográfica como um todo, pode contribuir para uma visão holística e integrada da análise espacial. 


\section{Referências}

CONGALTON, R. G.; GREEN, K (1999). Assessing the accuracy of remotely sensed data: principles and practices. New York: Lewis Publisher. 136 p.

GorelicK, N., Hancher, M., Dixon, M., Ilyuschenko, S., Thau, D., Moore, R. (2017). Google Earth Engine: Planetary - scale Geospatial Analysis for everyone. Remote Sensing of Environment. V. 202. P.18-27.

IBGE. Instituto Brasileiro de Geografia e Estatística. (1999). Manual Técnico de Uso da Terra. Manuais Técnicos em Geociências. no 7, $1^{\circ}$ edição. Rio de Janeiro.

IBGE. Instituto Brasileiro de Geografia e Estatística. (2013) Manual Técnico de Uso da Terra. Manuais Técnicos em Geociências. no 7, $3^{\circ}$ edição. Rio de Janeiro.

LANG, S., BLASCHKE, T. (2009). Análise da Paisagem com SIG. Oficina de Textos. São Paulo.

Projeto MapBiomas. Coleção 4.0 da Série Anual de Mapas de Cobertura e Uso de Solo do Brasil. Disponível em: https://mapbiomas.org/download. Acesso em 1 dez. 2019.

SEA / INEA. (2014). Elaboração do Plano Estadual de Recursos Hídricos do Estado do Rio de Janeiro. R2-F - Caracterização Ambiental. Fundação COPPETEC - Laboratório de Hidrologia e Estudos de Meio Ambiente. Rio de Janeiro.

SEA / INEA. (2018). Projeto de Mapeamento da Cobertura da Terra e de Detecção de Mudanças na Cobertura Florestal do Estado do Rio de Janeiro. Fundação COPPETEC - Laboratório Espaço de Sensoriamento Remoto e Estudos Ambientais. Rio de Janeiro. 2018.

WOODCOCK, C.E.; STRAHLER, A.H. (1987). The Factor Scale in Remote Sensing. Remote Sensing of Environment 21, 311-332.

WU, J. (2004). Hierarchy and Scaling: Extrapolating Information along a Scaling Ladder. Landscape Ecology 19: 125-138. 